\title{
UM CRIME AOS OLHOS DO HOMEM, UM PECADO AOS OLHOS DE DEUS: AS DESIGNAÇÕES DO ABORTO EM REVISTAS CATÓLICAS
}

\author{
A CRIME IN THE MAN'S EYES, A SIN IN GOD'S EYES: \\ THE DESIGNATIONS OF ABORTION IN CATHOLIC MAGAZINES \\ UN CRIMEN A LOS OJOS DEL HOMBRE, \\ UN PECADO A LOS OJOS DE DIOS: \\ LAS DESIGNACIONES DEL ABORTO EN REVISTAS CATÓLICAS
}

\author{
Aline Roes Dalmolin \\ Pós-doutoranda, Universidade \\ Federal de Santa Maria \\ dalmoline@gmail.com
}

\begin{abstract}
Resumo
$\mathrm{O}$ artigo relata resultados de pesquisa que aborda o discurso sobre aborto nas revistas católicas Rainha e Família Cristã nos anos 1980. O recorte temporal se justifica pelo fato de que, naquele momento, inaugura-se no Brasil o chamado "macroacontecimento aborto". Lança-se mão dos pressupostos teórico-metodológicos da análise de discurso de linha francesa, observando as designações do aborto na tentativa de ultrapassar o efeito de literalidade que adviria de uma suposta homogeneidade do discurso das revistas. Nas sequências discursivas analisadas, foram identificados dois conjuntos principais de designações: os que condenam o ato como "um crime aos olhos do homem" e os que o consideram "um pecado aos olhos de Deus". Conclui-se que as revistas católicas analisadas, apesar de designarem a prática do aborto como crime e pecado, de um modo geral, aconselham uma atitude de compreensão para com as mulheres que o praticam.
\end{abstract}

Palavras-chave: Revista. Discurso. Mídia e religião. 


\begin{abstract}
The article reports results of a study that board the discourse on abortion in Catholic magazines named Rainha and Família Cristã in the 1980s. The time frame is justified by the fact that, at that time, was inaugurated in Brazil something called "great event abortion". We use the theoretical and methodological assumptions of French discourse analysis, noting the names of abortion in an attempt to overcome the effect of literalness that would come from an assumed homogeneity of the discourse of the magazines. In the discursive sequences

analyzed, we identified two major sets of assignments: those who condemn the act as "a crime in the eyes of man" and who consider it "a sin in God's eyes". We conclude that the magazines, although designate the practice of abortion as a crime and sin in general, advise an attitude of understanding for women who practice it.
\end{abstract}

Key words: Magazine. Discourse. Media and religion.

\title{
Resumen
}

El artículo reporta los resultados de un estudio que aborda el discurso sobre el aborto en las revistas católicas Rainha y Família Cristã en la década de 1980. El marco de tiempo se justifica por el hecho de que, en esa época, se inauguró en Brasil algo llamado "macroacontecimento aborto". Se utilizan la presuposición teórica y metodológica de análisis del discurso de línea francesa, a observar los nombres de aborto en un intento de superar el efecto de la literalidad que vendría de una supuesta homogeneidad del discurso de las revistas. En las secuencias discursivas analizadas, se identificaron dos grandes grupos de tareas: los que condenan el acto como "un crimen a los ojos del hombre" y que consideran como "un pecado a los ojos de Dios". Llegamos a la conclusión de que las revistas, aunque designen la práctica del aborto como un crimen y el pecado, en general, aconsejan una actitud de comprensión con las mujeres que lo practican.

Palabras clave: Revistas. Discurso. Media y religión.

\section{INTRODUÇÃO}

O primeiro papa latino-americano da história da Igreja Católica, o argentino Jorge Mario Bergoglio, vem recebendo atenção por parte da mídia em razão de algumas de suas declarações, que criticam a rigidez pela qual a Igreja historicamente vem abordando questões de natureza sexual e reprodutiva como o divórcio, a homossexualidade e o aborto. Em agosto de 2013, em entrevista à revista jesuíta La Civiltà Cattolica (SPADARO, set 2013), o papa Francisco I reacendeu o debate ao criticar a Igreja por se concentrar naquilo que chama de "pequenos preceitos" e atitudes condenatórias, em vez de assumir uma atitude de acolhida para com todos os cristãos. Incitado a pronunciar-se a respeito do aborto, ele defendeu a necessidade de analisar o contexto de cada caso e ressaltou o papel de uma pastoral missionária, centrada no anúncio do evangelho, em vez de concentrar-se no que chama de "transmissão desarticulada de doutrinas". 
Non possiamo insistere solo sulle questioni legate ad aborto, matrimonio omosessuale e uso dei metodi contraccettivi. Questo non è possibile. Io non ho parlato molto di queste cose, e questo mi è stato rimproverato. Ma quando se ne parla, bisogna parlarne in un contesto. Il parere della Chiesa, del resto, lo si conosce, e io sono figlio della Chiesa, ma non è necessario parlarne in continuazione. Gli insegnamenti, tanto dogmatici quanto morali, non sono tutti equivalenti. Una pastorale missionaria non è ossessionata dalla trasmissione disarticolata di una moltitudine di dottrine da imporre con insistenza (...). (FRANCISCO I apud SPADARO, set 2013, p. 464) ${ }^{1}$.

Quando o papa Francisco I fala em "aborto", a palavra não resguarda apenas o sentido literal de sua definição obstétrica, que consiste na interrupção de uma gravidez antes que o embrião e o posterior feto possam sobreviver em ambiente extrauterino (PRADO, 1984). Dentre os sentidos aglutinados na expressão encontra-se a instauração de um debate que se articula a partir da dicotomia criminalização/descriminalização, independente, portanto, do aborto enquanto prática, presente no decorrer de praticamente toda a história da humanidade ${ }^{2}$. Nesse contexto, o aborto pode ser considerado

parte de um conjunto mais abrangente de demandas recentes pela definição legal de vida, pela regulação de políticas e técnicas de reprodução e pela implementação dos direitos sexuais e reprodutivos. É, contudo, um tema significado também de modo diverso, implicando em uma questão na qual a conformação cultural dos gêneros e o dualismo moderno entre natureza e cultura atua de forma particular (...). (CUNHA, 2007, p. 15).

Essas questões começam a serem pautadas a partir do final do século XIX, mas suas discussões só se intensificarão nas últimas décadas do século XX, sobretudo nos desdobramentos da chamada "revolução sexual". Parece ser consenso entre os pesquisadores que se debruçam sobre os discursos sobre aborto em suas diferentes dimensões que a "guerra do aborto" eclode no Brasil nos anos 1980 (LIBARDI DE SOUZA, 2009; WOITOWICZ, 2009; BRITES, 2011). Aquele momento caracteriza-se por "grandes modificações no mapa moral da nação", que contrabalançam tendências tão díspares como a consolidação dos valores laicos e liberais consagrados pela contracultura nos anos 1960 quanto o surgimento de novas de novas denominações neopentecostais, que aglutinam ao cenário religioso brasileiro novas versões da moralidade cristã (DUARTE, 2011).

\footnotetext{
1 "Não podemos insistir apenas sobre questões ligadas ao aborto, matrimônio homossexual e uso de métodos contraceptivos. Isso não é possível. Eu não falei muito dessas coisas, e me reprovaram por isso. Mas quando se fala, é preciso falar disso em um contexto. O ponto de vista da Igreja, de um modo geral, é conhecido, e eu sou filho da Igreja, mas é necessário ir adiante. Os ensinamentos, tanto dogmáticos quanto morais, não são todos equivalentes. Uma pastoral missionária não é obcecada com a transmissão desarticulada de uma multiplicidade de doutrinas e de impô-las com insistência (...)." [tradução livre da autora].

${ }^{2}$ A interrupção da gravidez e o uso de anticoncepcionais eram amplamente utilizados por mulheres gregas e romanas, através de métodos que se baseavam no uso de ervas medicinais e outras técnicas (PRADO, 1984).
} 
Sob um viés midiático, podemos pensar o aborto na ordem um macroacontecimento fundador (MAROCCO, 2004; MOREY, 1988), que ultrapassa os limites de uma temporalidade específica e limitada, oferece-se como uma das formas de pensar esse discurso que constantemente se sedimenta e se atualiza a partir dos mecanismos da memória, unindo as pontas entre o passado e o presente. Cabe aqui realçarmos o processo incessante através pelo qual um macroacontecimento fundador se instaura e se atualiza através de uma infinidade de microrrelatos "produzidos a sua imagem e semelhança" (MAROCCO, 2004, p. 23). Nesse sentido, inscrevemo-nos na perspectiva de Tuchman (1983), que focaliza as continuidades e descontinuidades desse tipo de acontecimento ${ }^{3}$ - considerado pela autora como aquele que "continua ao longo do tempo" - citando o sexismo como exemplo.

Los acontecimientos son discretos, se supone que tienen un comienzo, una fase media y un final. Incluso los acontecimientos (sucesos) que continúan a lo largo del tiempo, tales como el trámite de un proyecto legislativo o de un juicio, se supone que comienzan y terminan. Un proyecto de ley pasa a ser considerado por un comité legislativo. Un juicio es llamado a sentencia. ¿Acaso el sexismo comenzò cuando Betty Friedan (1963) llamó la atención hacia él considerándolo como "el problema que no tiene nombre"? ¿O el sexismo es un fenómeno en curso, presente en toda la historia humana, y por eso se trata de un fenómeno a ser descalificado como no noticiable? (TUCHMAN, 1983: 148-149).

O que dá o caráter "acontecimental” ao discurso sobre aborto se concretiza nos "fatos" que vão sendo aglutinados em torno do tema no Brasil no decorrer da década de 1980, bem como as discussões das pautas descriminalizatórias do assunto no congresso nacional que tomam corpo a partir de meados dos anos 1970. A esse contexto podemos somar uma ampla gama de microrelatos que atualizam o macroacontecimento, como o lançamento de manifestos a favor do aborto pelo movimento feminista, a implementação de políticas públicas pela saúde da mulher por parte do governo e a queda de braço entre feministas e católicos durante a Assembleia Constituinte.

Portanto, é a partir desse marco "acontecimental” que o aborto traduz na mídia seu caráter extremamente polêmico e mobilizador, à medida que os campos sociais (BOURDIEU, 2003), incitados pela disputa simbólica, tomam para si a tarefa de manifestar suas posições em sociedade. As revistas católicas, desse modo, desempenham um papel de "trincheira de combate cultural", buscando legitimar e promover a ideologia do catolicismo ao mesmo tempo em que representam uma interface de intersecção entre os campos religioso e midiático (DALMOLIN, 2010).

\footnotetext{
${ }^{3}$ Não nos estenderemos aqui ao esmiuçar as tipologias do acontecimento jornalístico, que podem ser observadas no estudo de Berger e Tavares (2010).
} 
Ao referir-se ao "parecer da Igreja" sobre o aborto, o papa enfatiza de forma específica os posicionamentos tomados pela Igreja, ao ocupar um dos polos que demarcam uma espécie de "cruzada moderna" desenrolada nas três últimas décadas. Desde o lançamento da "Declaração sobre o aborto provocado", documento lançado pela Santa Sé em 1974, vários outros documentos papais ${ }^{4}$ ofertam uma série de "falas" que balizam o posicionamento oficial da instituição, ofertando diretrizes aos católicos à luz dos evangelhos e da tradição da Igreja. Nesse sentido, o catolicismo vem norteando sua posição como de radical "defesa da vida", ao condenar o aborto em quaisquer contextos e circunstâncias e prescrevendo a pena de excomunhão aos fiéis que praticarem o ato (SANTA SÉ, 1983).
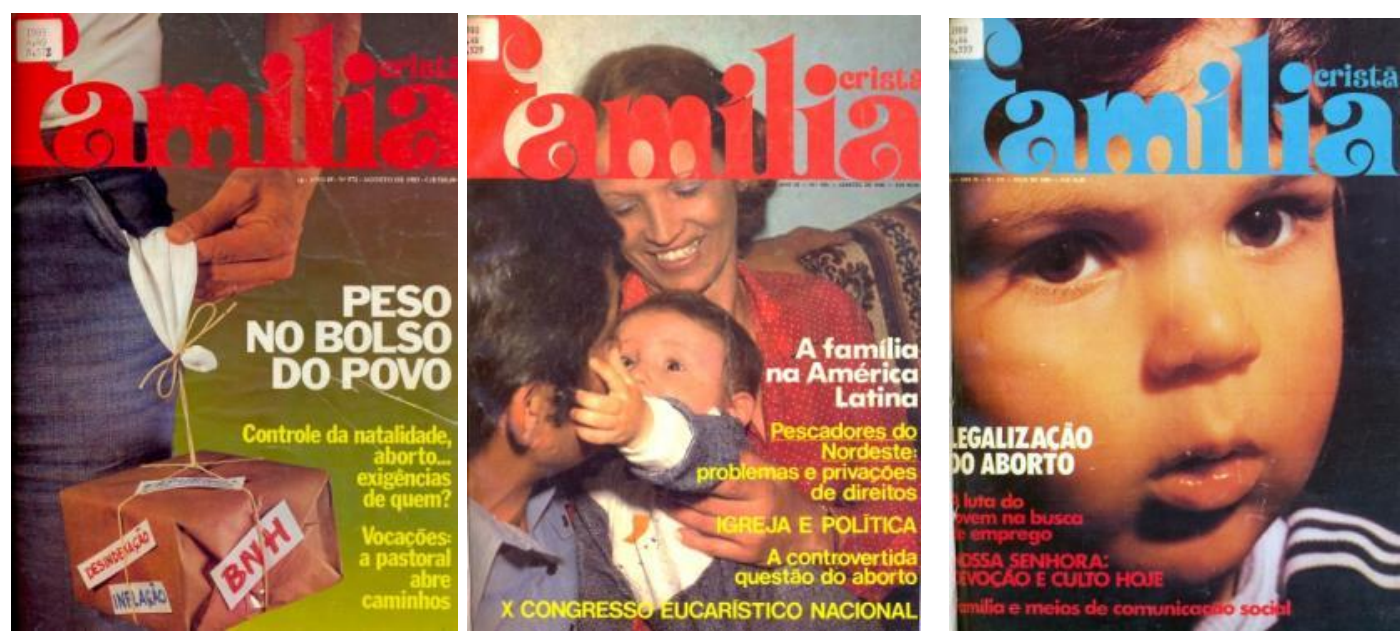

Figuras 1, 2 e 3 - capas de Família Cristã que destacam a questão do aborto.

Fonte: Arquivo Provincial Palotino - Santa Maria - RS

Essas posições são materializadas no discurso das revistas Família Cristã (Figuras 1, 2 e 3) e Rainha (Figuras 4, 5 e 6) no decorrer dos anos 1980. Ambas são de propriedade de congregações católicas: Rainha é o principal veículo dos padres palotinos, sendo editada no Rio Grande do Sul (Porto Alegre), enquanto Família Cristã pertence às irmãs paulinas, com sede em São Paulo (capital), sendo esta a revista de maior tiragem no país, posição que vem mantendo desde a década de 1980. Na época, as duas revistas, de ampla circulação nacional, levavam mensalmente aos seus assinantes informação e entretenimento, além de conteúdo religioso e os posicionamentos sobre questões polêmicas, como o aborto, que passaremos a analisar a partir de agora.

\footnotetext{
${ }^{4}$ O capítulo 4 de nossa tese de doutorado (DALMOLIN, 2012) analisa os posicionamentos sobre o aborto contidos nessa ampla gama de documentos pontifícios, bem como os pronunciamentos papais e as orientações da CNBB que canalizam essas orientações para o contexto brasileiro.
}

\section{ANIMUS}




\section{PROCEDIMENTOS E PERCURSOS METOdOlógicos: A ANGUlaÇÃo DISCURSIVA}

A pesquisa analisa as matérias sobre aborto publicadas em Rainha e Família Cristã, veiculadas entre janeiro de 1980 e dezembro de 1990 - abarcando, portanto, 11 anos de história das revistas - período no qual foram editadas 121 edições de Rainha ${ }^{5}$ e 132 edições de Família Cristã ${ }^{6}$. Em ambas as revistas, o assunto é abordado em reportagens, artigos, entrevistas, notícias e seções de cartas do leitor, Em Rainha, o aborto aparece na maior parte das vezes referido no formato de notícias, enquanto em FC o tema veicula-se com maior frequência no formato reportagem. Nosso recorte foca-se no conteúdo jornalístico, deixando de lado as seções de comentários dos leitores ${ }^{7}$.
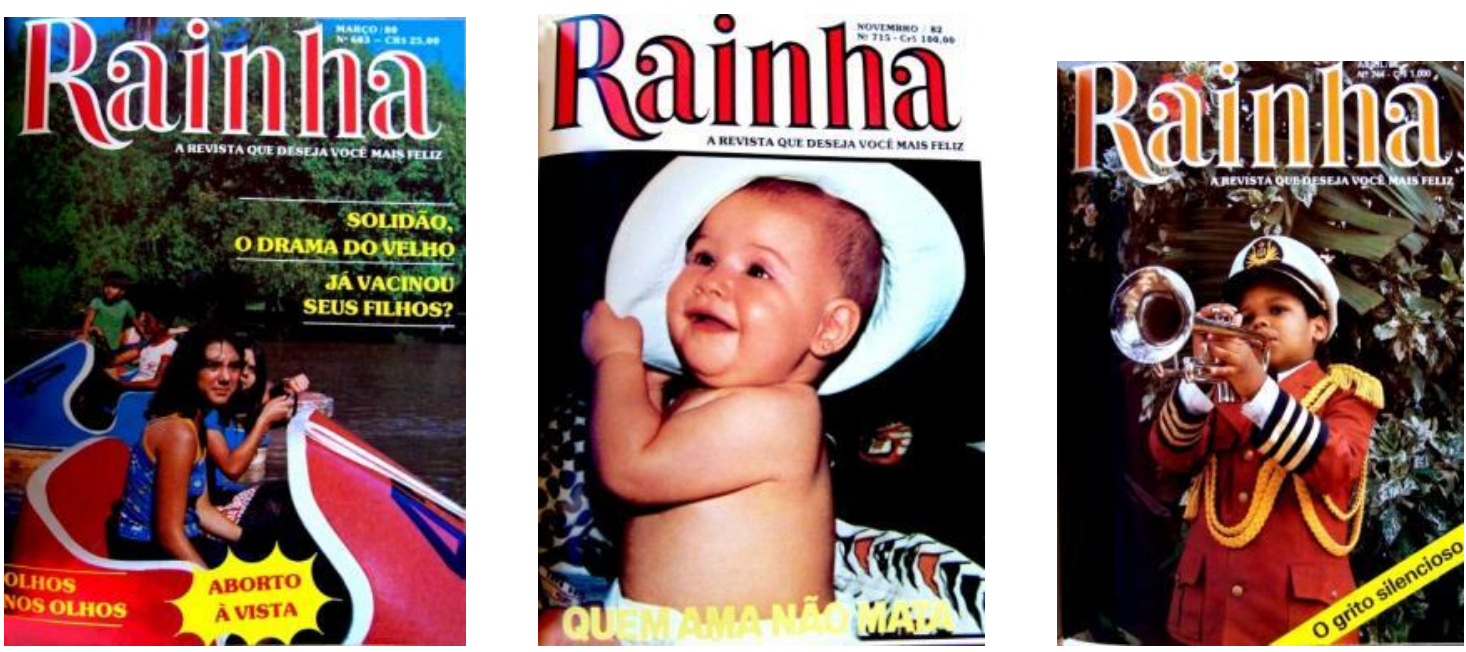

Figuras 4, 5 e 6 - capas de Rainha que fazem referência à matérias sobre aborto Fonte: Arquivo Provincial Palotino - Santa Maria - RS

Cabe destacar que a seleção das sequências discursivas a serem analisadas pautou-se

\footnotetext{
${ }^{5}$ Rainha tradicionalmente veicula somente uma edição nos meses de janeiro e fevereiro, totalizando 11 edições anuais.

${ }^{6}$ Para a construção do corpus discursivo, observamos edições aleatórias de cada revista, ao todo, 60 edições de Família Crist $\tilde{a}^{\sigma}$ e 61 de Rainha, totalizando 121 exemplares das revistas. Deste recorte, selecionamos um agrupamento de 133 sequências discursivas, observadas a partir de dois movimentos de análise que descreveremos adiante.

${ }^{7}$ Estas são denominadas "Confidencial", em Rainha; "Nosso cantinho", "Cartas do Mês" e "Opinião do Leitor", em Família Cristã. No recorte das sequências discursivas, lançamos mão das diferentes seções nas quais o aborto serviu de pauta, contudo deixamos de analisar as matérias de seções do tipo "carta ao leitor" pois suas especificidades suscitariam um olhar mais detalhado, e por isso implicando que fossem abarcadas de forma diferenciada das demais. No entanto, as percepções dos leitores revelam-se bastante similares em seu conjunto. $\mathrm{Na}$ maioria das vezes expressam apenas uma valoração positiva dos modos de abordagem da revista, sempre mostrando uma visão de concordância com as posturas editoriais e rejeitando fortemente a possibilidade de se praticar aborto.
} 
por critérios de exaustividade, representatividade e homogeneidade (COURTINE, 1981), que se orientam no sentido de, respectivamente, não deixar de observar nenhuma variável que tenha intrigado ao pesquisador, não extrair leis gerais de aspectos discursivos verificados uma única vez e de organizá-los no sentido de observar a coerência discursiva dos mesmos. No entanto, apesar de assumirmos esses critérios, a apropriação não se deu por um viés quantitativo, sustentados pelo pressuposto da $\mathrm{AD}$ segundo o qual a apreensão das regularidades não está condicionada ao acúmulo quantitativo de dados (MARIANI, 1998). Trata-se, portanto, de um recorte construído na verticalidade, uma vez que não nos interessa "quantificar a presença de determinadas marcas, mas olhar para o funcionamento discursivo dessas marcas" (GRIGOLETTO, 2005, p. 118), ou seja, os mecanismos de construção do discurso jornalístico (BENETTI, 2007).

Sustentados pela noção de interdiscurso, concordamos com Maingueneau (1993, p. 14) ao afirmar que um corpus não interessa por sua singularidade ou enquanto produto de um sujeito determinado, mas por "considerar sua enunciação como o correlato de uma certa posição sócio histórica na qual os enunciadores se revelam substituíveis" (grifo do autor). Portanto, cada sequência discursiva é tomada por sua condição enquanto discurso da revista, independente dos sujeitos empíricos que efetivamente o proferiram na situação historicamente localizada.

Tentaremos com isso estabelecer um olhar que ultrapasse o "efeito de literalidade" proporcionado pela suposta homogeneidade do discurso das revistas que uma leitura apressada das mesmas poderia sugerir, segundo a qual estas estariam reduzidas enquanto expressão de uma contrariedade irrestrita a qualquer tipo de prática voltada à interrupção voluntária de uma gravidez. Esse efeito de literalidade toma dimensões importantes à medida que se toma em mãos um discurso ideologicamente demarcado como o das revistas católicas. Conforme salienta Benetti (2007, p. 108), "quanto mais naturalizada a ideologia, mais as formações discursivas que dela derivam carregam sentidos que parecem literais." Partindo de um dos pressupostos mais caros à $\mathrm{AD}$, o da opacidade da linguagem, cabe ao analista buscar ir além desse "efeito de literalidade" e interpretar os sentidos que o compõe.

Este movimento de interpretação do corpus discursivo tem por intuito compreender, de um modo geral, como se dá o discurso sobre aborto nos casos em análise. Procuraremos evidenciar as principais angulações e tipos de abordagem do discurso das revistas sobre o tema, a partir da observação dos principais processos de designação do aborto.

As designações podem ser compreendidas como modos através dos quais um enunciador apresenta o referente em um determinado enunciado. O fundamental, nesse 
movimento de significação, reside no ato do enunciador fazer referência, mas às estratégias discursivas pelas quais o enunciador passa ao coenunciador as instruções necessárias para identificar os referentes num determinado contexto (MAINGUENEAU, 2008). Portanto, em nosso gesto de interpretação, nos interessa sobremodo reportar não somente às designações em si, elencando e ordenando de forma suficientemente exaustiva as designações utilizadas pelo sujeito enunciador para se referir ao aborto, mas principalmente ao modo de atuação dos mecanismos de identificação entre contextos e referentes.

Segundo Indursky (1999), as designações são estruturadas pelas formações ideológicas e fortemente determinadas pelo imaginário dos sujeitos sociais envolvidos. As formações ideológicas, por sua vez, são representadas no discurso através das formações discursivas (PÊCHEUX, 1995), determinando os sentidos numa situação e numa conjuntura dadas. Desse modo, ao elencarmos algumas das principais designações, de certa forma tentaremos esboçar um primeiro movimento de observar as formações discursivas ${ }^{8} \mathrm{e}$ ideológicas.

\subsection{Crime e castigo: a análise das designações do aborto}

Nesse item, buscarei enfocar os principais processos de designação do aborto nos domínios discursivos de Rainha e de Família Cristã. Identificamos nas revistas dois modos principais de identificação, que percebem o aborto como crime e o aborto como pecado. Nossa análise, portanto, circundam dois eixos que reportam a uma articulação que compreende o ato do aborto pelo viés religioso (pecado) - portanto condenado pelas leis divinas -, e secular (crime) - passível de punição pela lei dos homens.

\subsubsection{Um crime aos olhos dos homens}

No primeiro modo de abordagem, o aborto é percebido como um crime. A essa perspectiva alude a maior parte das designações do aborto de cunho secular encontradas em nosso corpus discursivo, algumas delas elencadas abaixo, em ordem alfabética.

\footnotetext{
${ }^{8}$ Procedemos a análise das formações discursivas em nossa tese de doutorado, cujo sexto capítulo ("O discurso sobre aborto em Rainha e Família Cristã") originou parte das discussões contidas neste artigo.
} 


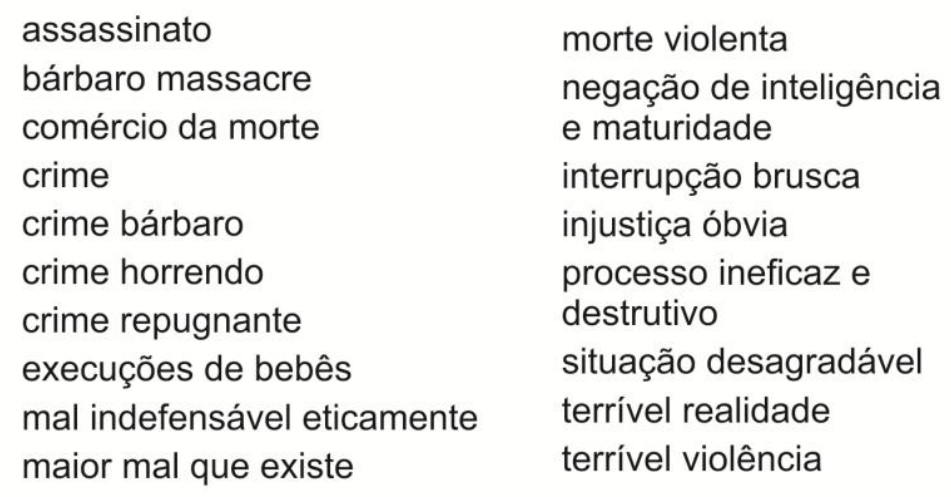

Quadro 1 - Designações do aborto em Rainha e Família Cristã.

Fonte: elaboração própria da autora.

Chama a atenção o fato de que as designações, quando não deixam evidente o caráter "criminoso" do ato (crime repugnante, crime violento, crime bárbaro, assassinato, execuções de bebês), reportam ao caráter de violência que nele estaria contido (interrupção brusca, morte violenta, terrível violência, bárbaro massacre). Outras fazem relação a uma imposição de valores (situação desagradável, mal indefensável eticamente, injustiça óbvia, processo ineficaz e destrutivo, interrupção brusca), mobilizada por uma avaliação do ato do abortamento sob o ponto de vista moral. Revela-se também uma constituição de sentido marcada pela negatividade, presente nos movimentos parafrásticos nos quais pequenas modificações vão sendo incorporadas às regiões de sentido sedimentadas, a exemplo das designações em torno das palavras "crime" ("crime repugnante", "crime horrendo", "crime bárbaro") e "terrível” (“terrível violência", "terrível realidade”).

O caráter criminoso e a condição ilegal do abortamento encontram-se enfatizadas nas sequências discursivas que descreveremos a seguir. A SD7 reporta ao aborto como "assassinato" e aos indivíduos que o praticam como "assassinos". Já na SD1, a relação entre os trechos destacados - "é legalmente considerado um crime" e "punido por lei" -, evidencia, a partir do uso dos verbos no presente do indicativo (“é”) e futuro do condicional (“deveria”), uma relação causal entre o que de fato ocorre (ser considerado um crime) e o que nem sempre se verifica na prática (a punição legal).

(SD7) Então vamos liberar o assassinato para que os assassinos (as) não corram risco? Isto é demais! É quase a mesma coisa que proibir o banco tocar o alarme, para evitar que a polícia chegue e prenda os ladrões... (“Aborto já!”. RH, No 805, set 1990, p. 50). 
(SD1) Atualmente, o aborto é provocado com muita frequiência. As estatísticas não conseguem dar um número exato, pois os abortos, em geral, são praticados às escondidas. Isto acontece porque, em muitos países, como no Brasil, ele é legalmente considerado um crime, portanto, deveria ser punido por lei; e mesmo nos países em que ele não é proibido por lei, as pessoas preferem esconder a ação que praticam. ("Aborto: um pecado social". FC, $\mathrm{N}^{\circ} 529$, jan 1980, p. 9).

Os trechos acima tenta evidenciar o caráter velado do ato do aborto, seja permitido por lei ou não ("em geral, são praticados às escondidas"). O texto enfatiza que, mesmo nos países em que a prática é legalizada, o ato não deixa de constranger moralmente quem aborta, conforme evoca o trecho "as pessoas preferem esconder a ação que praticam". A sequência reporta, portanto, a um movimento discursivo que procura argumentar que, independentemente do ato do aborto ser permitido por lei ou não, a prática representa um motivo de vergonha e constrangimento.

Um dos movimentos interessantes, encontrado especificamente no domínio discursivo da revista Rainha, é o que compara o ato do aborto ao holocausto nazista. À primeira vista, chama a atenção o uso dos adjetivos "assombrosos", "repugnantes", "terríveis", que podem ser associados ao "horror" característico da experiência do holocausto.

(SD9) Uma das conferências que despertou maior atenção e causou grande surpresa foi a do cientista Bernard Nathanson, ex-abortista, que relatou os diversos e assombrosos experimentos que se estão realizando em engenharia genética, incluindo a hibridação entre fetos humanos e animais. Nathanson, hoje convertido num dos maiores defensores da vida, afirmou que "frente aos horrores que se realizam hoje, os terríveis experimentos dos nazistas com os prisioneiros judeus podem ser considerados jogos de crianças". ("A cada ao são praticados 40 milhões de abortos no mundo". RH, $\mathrm{N}^{\circ} 794$, set 1989, p. 48).

(SD10) Outra situação que preocupa os movimentos pro-life é o uso dos fetos, que a sentença Roe versus Wade tornou praticamente disponíveis para todo e qualquer uso. Dos vagões abarrotados de fetos mortos, destinados às fábricas de sabonetes e cosméticos, passou-se às experimentações nos fetos ainda vivos, cujos tecidos são utilizados para transplantes. Basta dizer que em 45 dos 50 Estados dos Estados Unidos, está legalizado o uso dos tecidos fetais. ("Mulheres, denunciem os que as fazem abortar". RH, $\mathrm{N}^{\circ} 772$, set 1987, p. 33).

(SD11) O aborto atinge cifras de holocausto no Japão. ("O jardim dos bebês de pedra". RH, $\mathrm{N}^{\circ} 775$, dez 1987, p. 34).

(SD12) Mas também questiono a responsabilidade de todos aqueles que, tendo um mínimo de consciência, compactuam com estas situações, seja por 
ambição de mais ter, seja por comodismo e omissão, seja por covardia de utilizarem todo o seu potencial, não importa de que tamanho for, para denunciar, combater e até mesmo impedir que assassinatos em massa, tão repugnantes quanto o massacre de milhões de judeus na segunda guerra, sejam realizados debaixo de olhares complacentes, relativizantes, de todos aqueles que, alienada ou comodamente dizem: "isto não é problema meu!" esquecidos de que fazem parte integrante da humanidade e de que cada coisa que acontece ao menor de nossos irmãos homens, é como se a nós mesmo tivesse ocorrido. ("RU-486: Pílula do aborto". RH, No 753, jan 1986, p. $31)$.

As duas primeiras sequências (SD9 e SD 10) referem-se à posterior utilização dos fetos após o ato do aborto. A SD 10 não faz referência direta às denominações presentes nas demais sequências (nazistas, holocausto e judeus, presentes nas SDs 9, 11 e 12, respectivamente), mas alude à experiência do holocausto por uma relação indireta. Perfazem essa relação de sentidos tanto a expressão "vagões abarrotados de fetos mortos" (SD10) - que pode remeter ao imaginário que reporta aos trens repletos de mortos eram retirados dos campos de concentração para serem aproveitados pelas indústrias nazistas -, quanto a expressão "experimentações nos fetos ainda vivos", que pode ser relacionada às execráveis experiências "científicas" com seres humanos vivos realizadas por Josef Menghele. Diversamente das demais SDs, que colocam o aborto e a experiência nazista a um nível de valoração equivalente (conforme evidencia a SD12, com o uso dos modalizadores "tão" e "quanto"), a SD9 considera as experiências realizadas com os fetos abortados nos Estados Unidos - designadas como "horrores" - mais condenáveis do que as feitas com os judeus durante o Terceiro Reich - qualificadas no texto como "terríveis". Estas últimas são consideradas "jogos de crianças" em relação às primeiras (SD9).

Já as SDs 11 e 12 comparam o caráter "massivo" das mortes em decorrência do aborto às promovidas pelo nazismo. A SD 11 usa a expressão "cifras de holocausto" para referir-se ao número de abortos praticados no Japão, quase 20 milhões no decorrer de quarenta anos, conforme cita a matéria da qual a SD foi retirada. Já a SD 12 lança mão da designação "assassinato em massa" para fazer menção ao aborto, sustentando que as mortes em decorrência do ato são "tão repugnantes quanto o massacre de milhões de judeus na segunda guerra".

Os movimentos de paráfrase ou de identificação com pré-construídos importados de outras formações discursivas também estão presentes nos processos de designação que passaremos a analisar a partir de agora. Estas reportam a uma matriz de significação religiosa, que percebe o aborto enquanto pecado. Do mesmo modo que os supracitados, os fragmentos recortados apontam para um mecanismo de atualização da memória, reportando para outras 
instâncias discursivas.

\subsubsection{Um pecado aos olhos de Deus}

A ambivalência que condena o aborto tanto em seu aspecto jurídico-secular quanto pelos preceitos religiosos fica evidente na sequência discursiva seguinte. A designação do aborto como pecado aparece associada ao quinto mandamento da lei divina, o de "não matar". O uso da expressão "muito mais pecado" modaliza a situação, tornando-na ainda mais condenável, justificada pela "covardia" embutida no ato de "matar um embrião, que não pode reagir".

(SD2) Trata-se de um crime perante a lei do país e de gravíssimo pecado perante Deus, que diz taxativamente: "Não matarás!". E matar um embrião, que não pode reagir, deve ser muito mais covardia, por isso muito mais pecado. (“Genoíno, o aborteiro". RH, N 801, mai 1990, p. 37).

As sequências que reportaremos a seguir apresentam uma dimensão do aborto como "pecado" pelo fato deste eliminar a vida de um "inocente". Uma imagem bíblica recorrente na apresentação do argumento religioso no domínio discursivo da revista Rainha associa o aborto ao episódio conhecido como o "massacre dos inocentes", segundo o qual o rei Herodes, após ficar sabendo do nascimento do suposto "rei dos Judeus" pela vinda de três magos vindos do oriente, manda matar todas as crianças de Israel menores de dois anos (Mt 2, 1-18). Nas SDs abaixo, a memória do tempo de Jesus é atualizada no discurso das revistas, que fazem menção não só ao aborto mas também àqueles que defendem a sua prática. Nesse movimento discursivo a prática contemporânea de interromper uma gravidez indesejada é comparada ao assassinato de bebês promovido por um rei na antiguidade.

(SD6) Ouviu bem, senhor Genoíno? E daí? Depois dessa, ainda vai querer levar adiante a sua suja campanha, feito um genuíno Herodes? Um novo matador dos nossos pequenos inocentes? ("Genoíno, o aborteiro". $\mathrm{RH}, \mathrm{N}^{\circ}$ 801, mai 1990, p. 38).

(SD8) Continuou o biólogo: "As sinistras silhuetas de guilhotina e dos carrascos não serão mais vistas nos pátios dos cárceres. Porém, acontece que em nossos hospitais se realiza o bárbaro massacre de centenas de inocentes." ("Pena de morte continua através do aborto". RH, $\mathrm{N}^{\circ} 712$, ago 1982, p. 47).

(SD15) Na arquidiocese de Milwaukee, nos Estados Unidos, as mães que praticaram o aborto e que sofrem pelas consequiências de seu ato e pelo afastamento da comunidade eclesial entram num projeto pastoral de aproximação e de conforto. Vicki Thorn é a coordenadora do projeto, que toma o nome da bíblica mãe que chora porque os seus fillhos já não existem. ("Raquel, não chores mais". RH, N 750 , out 1985, p. 20). 
O primeiro trecho (SD6) associa a figura de Herodes, o mentor da matança, ao deputado José Genoíno, autor de um projeto pela legalização do aborto (PL 3405/1989), que na época da publicação da matéria encontrava-se em tramitação no parlamento. $\mathrm{O}$ enunciador busca desqualificar sua ação, colocando Genoíno no lugar de Herodes como "um novo matador", responsabilizando-o portanto pelas mortes dos fetos que viriam a ser abortados caso a lei fosse aprovada e entrasse em vigor, designados no texto pela expressão "pequenos inocentes". Adiciona-se o efeito de sentido proporcionado pelo jogo de palavras entre o nome do deputado (Genoíno) ao adjetivo homófono (genuíno) anteposto à palavra Herodes.

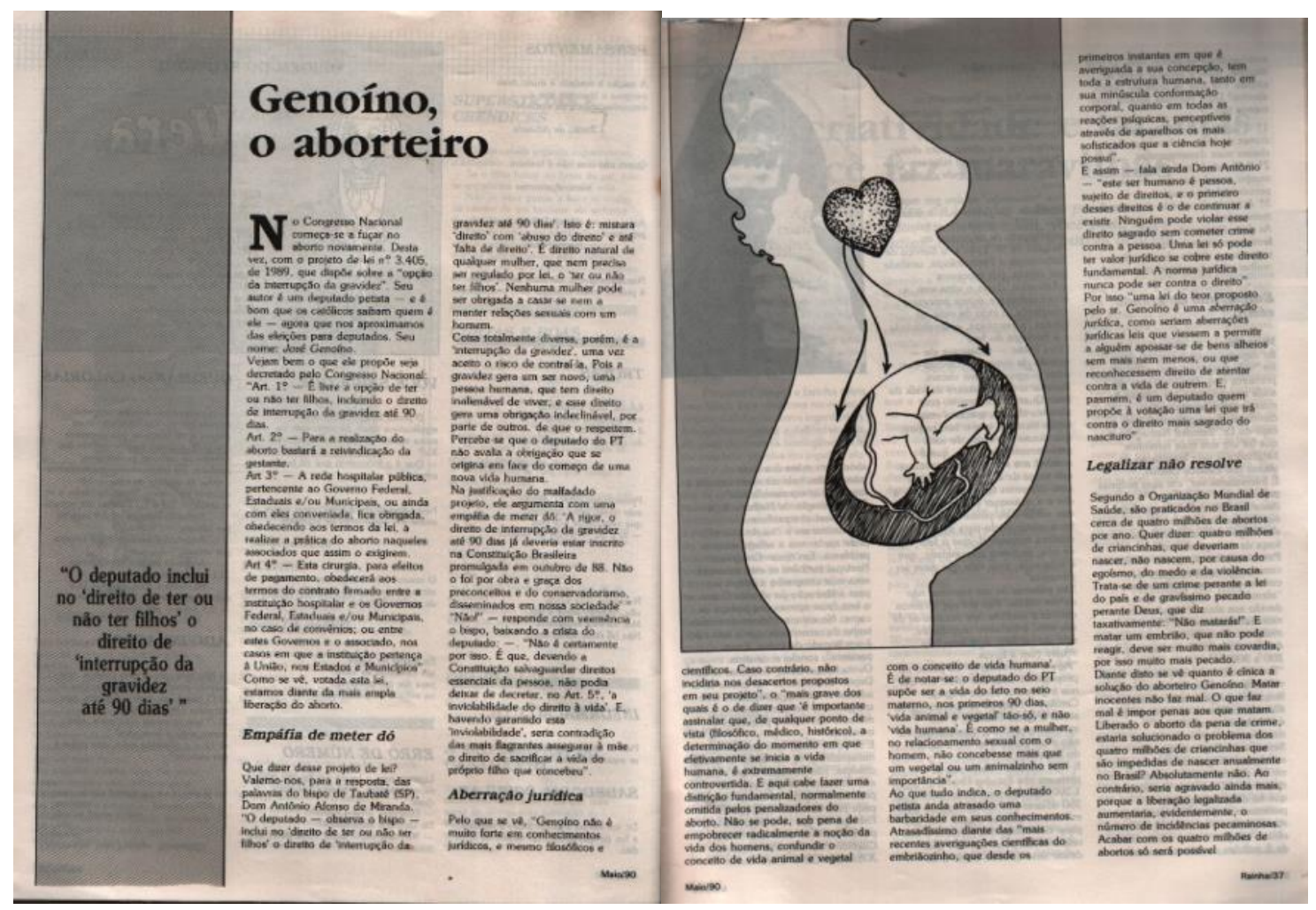

Figura 7 - Matéria “Genoíno, o aborteiro” (RH, N 801, mai 1990, pp. 38-39).

Fonte: Arquivo pessoal da autora.

Já a segunda sequência (SD8) reporta ao mesmo episódio bíblico através da designação "bárbaro massacre de inocentes". No entanto, o mecanismo parafrástico proposto pelo enunciador da frase aciona uma memória discursiva pertencente a outro tempo histórico, à pena de morte nas guilhotinas da Revolução Francesa, através da expressão "silhuetas de guilhotina e de carrascos". Isso se faz evidente no próprio texto da notícia da qual pertence o trecho selecionado, que reporta às declarações de um biólogo francês em relação à abolição da pena de morte naquele país, nas quais sustenta que enquanto houver aborto, a pena de morte permanecerá vigente.

$$
\text { ANIMUS } \begin{aligned}
& \text { Revista Interamericana de Comunicação Midiática } \\
& \text { E-Issn 2175-4977 | v.12 n.24 | } 2013 \text { | www.ufsm.br/animus }
\end{aligned}
$$


A SD15, por sua vez, reporta a outra personagem do episódio bíblico do "massacre dos inocentes". Raquel, a “bíblica mãe que chora porque os seus filhos já não existem”, dá nome ao projeto aludido pela matéria da qual foi retirada a sequência (Projeto Raquel), e ao mesmo tempo serve de metáfora para denominar as mulheres que abortam e sofrem por isso. A mulher que aborta, desse modo, é discursivamente apresentada não como uma "assassina", mas como a mãe que sofre e chora por seus filhos, arcando com as conseqüências de seu ato.

Em outros trechos, a percepção do feto como um "inocente indefeso" e outras designações similares também podem ser reportadas ao contexto bíblico, mesmo que o texto não faça menção explícita à Herodes ou ao massacre dos inocentes. A SD3 enfatiza uma postura religiosa pelo uso da expressão "lei natural e divina", enquanto a SD4 manifesta uma perspectiva mais "secular" pela referência à questão da "paz".

(SD3) A CNBB recorda que, por lei natural e divina, o aborto é um crime contra um inocente indefeso. Em uma época em que se acentuam tanto os direitos humanos, convém frisar que o direito à vida pertence a todos e muito menos em se tratando de alguém que não tem condições de se defender. Legalizar o aborto seria ir contra a lei da vida, seria uma tentativa de legalizar uma injustiça óbvia. (“Aborto: crime contra inocentes". $\mathrm{RH}, \mathrm{N}^{\circ}$ 718, fev 1983, p. 46).

(SD4) "O aborto é o maior mal que existe e o maior destruidor da paz, porque é um terrível assassino que termina com a vida dos indefesos". ("Madre Tereza condena aborto". RH, N 755, mar 1986, p. 47-48).

Uma outra dimensão do aborto enquanto pecado, explorada principalmente pelo domínio discursivo Família Cristã, é a do aborto enquanto "pecado social”. A própria designação trabalha um acionamento interessante que articula o religioso (pecado) ao secular (social), pensando o pecado não a partir de uma instância pessoal e de foro privado, mas relacionando-o a um grupamento social ou generalizando ao conjunto da sociedade. "Toda a sociedade tem um influxo e uma responsabilidade bem grande em quase cada um dos abortos praticados no mundo" (SD28).

Ganha espaço um movimento discursivo que dissocia a prática do aborto de uma dimensão individual, cuja pena impetrada pela doutrina àqueles que o praticam é a excomunhão, para frisar a culpabilidade da sociedade como um todo pelo ato. Nos trechos assinalados, não se nega a dimensão da culpa individual da mãe que pratica o aborto, como demonstra o trecho: "Não se pode dizer simplesmente que a mãe solteira, que aborta uma vez por ano, não esteja vivendo nenhum pecado" (SD26), contudo, esse fator é minimizado ao se enfatizar que a culpa ultrapassa a dimensão individual da "mãe-gestante" (SD28). Ressalta-se 
a necessidade de comprometimento da "família", da "sociedade" e do "rapaz responsável pelo ato" (SD25) de arcar com as consequências do ocorrido.

(SD25) E nas ocasiões em que a jovem solteira engravida, mas não tem condições de ter e educar o filho, o que fazer? Trata-se, com efeito, de um problema real e mais freqüente do que se pensa. Em tais circunstâncias é que a família, a sociedade e o rapaz responsável pelo acontecimento devem proteger, ajudar, amparar e atender as necessidades da jovem mãe. (“Aspectos psicológicos do aborto". RH, N 790, mai 1989, p.21).

(SD26) Então, nestas circunstâncias, o aborto não é um mal moral? Não é um pecado? Não há dúvida que há um pecado, uma banalização da pessoa humana, um atentado contra a vida. Mas deve-se perguntar de quem é o pecado e em que grau de responsabilidade. Não se pode dizer simplesmente que a mãe solteira, que aborta uma vez por ano, não esteja vivendo nenhum pecado. Mas não se pode deixar de considerar também que ela é, frequentemente, envolvida e massacrada por um pecado que não é só dela. Exige-se da mãe solteira amor, doação, responsabilidade e compromisso, quando ninguém a ama de fato, nem se compromete com ela. ("Responsabilidade pessoal diante do aborto". FC, $\mathrm{N}^{\circ} 530$, fev 1980, p. 10).

(SD27) Aqui entra o fato muito importante do homem estar habituado a ver a maternidade e o aborto em termos de mãe ou casal, no máximo em termos de família. Mas, na verdade, o seu contexto é muito mais amplo e nunca se pode deixar uma maternidade à responsabilidade exclusivamente individual. A mãe não só precisa estar livre de pressões para gerar a nova vida, mas ser positivamente incentivada, encorajada, amada, para permitir, em nome de todos os que a rodeiam, o milagre da vida. ("Responsabilidade pessoal diante do aborto". FC, $\mathrm{N}^{\circ}$ 530, fev 1980, p. 10).

(SD28) Numa análise mais atenta desses motivos, percebe-se que eles têm uma raiz social muito profunda, de modo que seria uma grande ingenuidade pensar que a provocação de um aborto é responsabilidade exclusiva da mãegestante. Toda a sociedade tem um influxo e uma responsabilidade bem grande em quase cada um dos abortos praticados no mundo. (“Aborto: um pecado social". FC, $\mathrm{N}^{\circ} 529$, jan 1980, p. 9).

As duas primeiras sequências discursivas (SD25 e SD26) referem-se à gravidez fora do âmbito matrimonial, o que é condenado pela Igreja. Os fragmentos não usam os termos "gravidez indesejada", mas reportam a situações hipotéticas que narram as dificuldades que ter um filho fora do casamento pode acarretar, "nas ocasiões em que a jovem solteira engravida, mas não tem condições de ter e educar o filho" (SD25). A SD26 enfatiza as dificuldades da mãe solteira com as em cumprir para com as exigências da maternidade sem alguém para lhe dar suporte: "Exige-se da mãe solteira amor, doação, responsabilidade e compromisso, quando ninguém a ama de fato, nem se compromete com ela" (SD26). Apenas a terceira sequência (SD27) cogita a ocorrência de aborto no âmbito da família. 


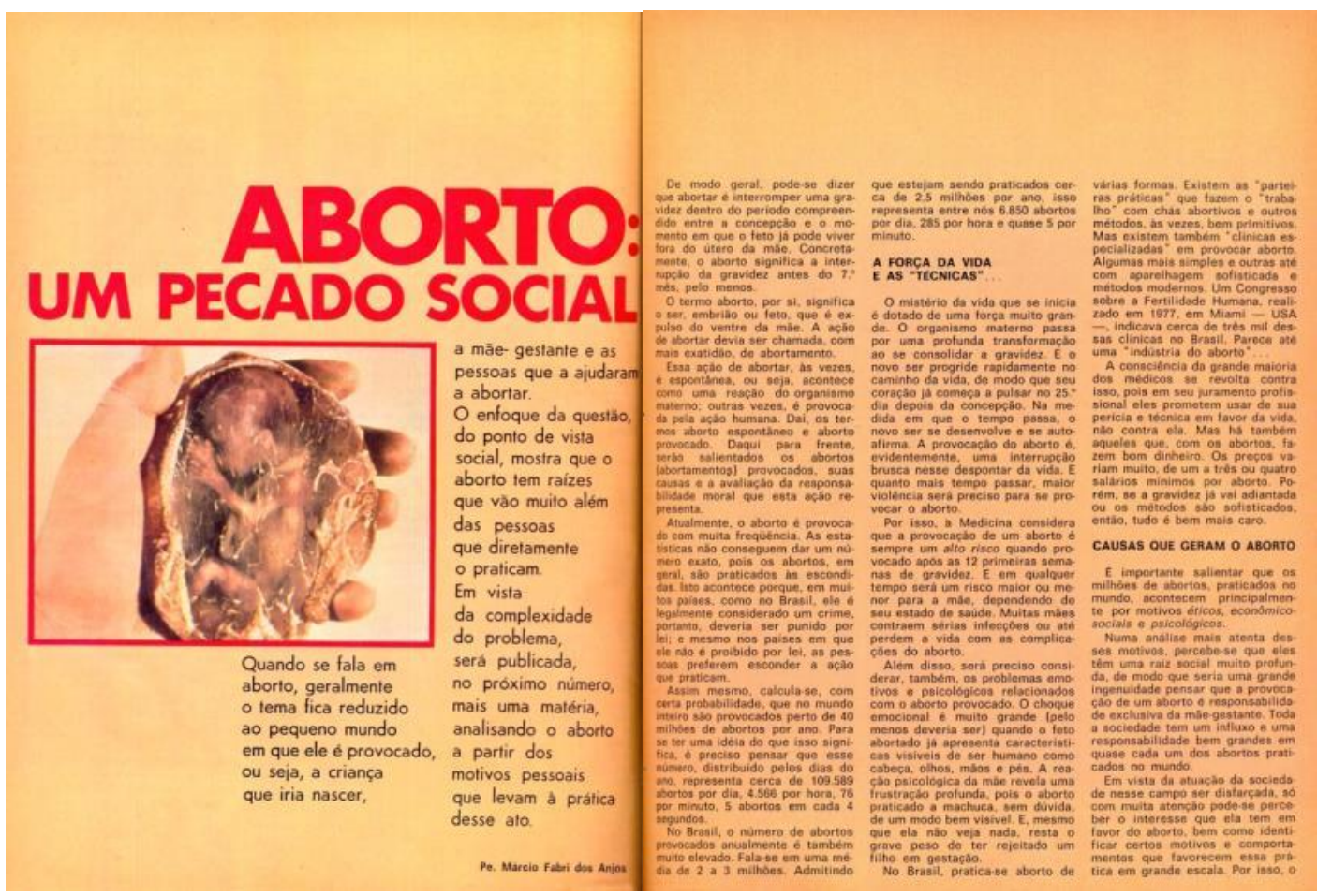

Figura 8 - Matéria de Pe. Marcio Fabri dos Anjos, “Aborto: um pecado social” (FC, N 529, jan 1980, pp. 8-9). Fonte: Arquivo Provincial Palotino - Santa Maria - RS.

Salienta-se também a presença de termos relacionados aos papeis familiares para designar a mulher. Para referirem-se à mulher que engravida, as SDs utilizam denominações relacionadas à maternidade: "jovem mãe" (SD25), "mãe solteira" (SD26), "mãe” (SD27) e "mãe-gestante" (SD28). Desse modo, realça-se o papel social imputado a esta independente da gravidez ser levada a termo ou não. Diferentemente, a primeira sequência trata o homem de maneira diversa, identificando-o não como o "pai" do futuro filho, mas designando-o como “o rapaz responsável pelo acontecimento" (SD25).

Deste outro conjunto de sequências podemos estabelecer uma relação de proximidade para com uma outra região discursiva, que se referem à complacência para com a mãe que aborta. Todas as SDs a seguir pertencem ao domínio discursivo Rainha.

(SD129) Um perito em leis canônicas, o padre Eugene Fitzsimmons, explicou a atual posição da Igreja em relação ao aborto: um pecado sempre gravíssimo, mas que não comporta automaticamente a excomunhão se a mulher envolvida é menor ou está exposta a pressões tais que compromete as suas capacidades críticas. Ainda hoje, para a Conferência Episcopal Americana, continua sendo um pecado "reservado", isto é, cuja absolvição está reservada ao bispo ou a um padre por ele delegado. Mas essa delegação, o arcebispo Rembert Weakland, de Milwaukee - no quadro do "Projeto Raquel" - a estendeu a todos os padres da sua arquidiocese. ("Raquel, não chores mais". RH, $\mathrm{N}^{\circ} 750$, out 1985 , p. 22). 
(SD130) Se a mulher é católica, cedo ou tarde se dá conta de ter praticado um gesto que a Igreja condena como culpa grave; muitas vezes é a primeira verdadeira culpa grave de uma mulher. Em teoria, todas deveriam saber que existe perdão para qualquer tipo de pecado, portanto, também para o aborto. (“Raquel, não chores mais". RH, No 750 , out 1985, p. 22).

(SD23) É melhor compreender e proteger do que castigar. No caso de ela ter decidido pelo aborto, ninguém tem o direito de jogar-lhe a primeira pedra. É preciso repetir a palavra de Cristo: "Vai em paz, filha, não queiras mais pecar". O amor sempre redime e salva. ("Aspectos psicológicos do aborto". RH, No 790 , mai 1989, p. 20-1).

Apesar de condenar o aborto como "culpa grave" e "pecado gravíssimo", as SDs acima relativizam a culpabilização das praticantes através de alusões à prática da confissão. As SDs 129 e 130 reportam diretamente a essa região de sentidos, evidenciadas pelo uso das sentenças "absolvição" (SD129) e "perdão" (SD130). Já a SD23 cita uma frase que é comumente dita pelo padre confessor após administrar o sacramento: "Vai em paz filha, não queiras mais pecar". A mesma sequência também aciona uma memória discursiva ancorada em referências bíblicas ao evangelho, através da alusão à parábola da mulher adúltera que o texto faz no trecho "No caso de ela ter decidido pelo aborto, ninguém tem o direito de jogarlhe a primeira pedra" (SD23). Fica implícito, portanto, que apesar de grave, o pecado do aborto é passível de perdão mediante apenas o arrependimento de quem o pratica.

As sequências abaixo salientam as consequências físicas e psicológicas do aborto provocado. Relatam-se repercussões físicas de considerável gravidade, expressas como "desastrosas" (SD21), que vão de "sérias infecções" (SD 22) à "perda do útero" (SD21), chegando até a morte da mulher (SD 22). Dentre as consequências psicológicas, destaca-se como principal o sentimento de culpa, acompanhada por uma gama de reações negativas que podem desencadear sentimentos de ordem depressiva e inclusive gerar a "agressividade contra si mesma e contra o companheiro, no qual se projeta a própria insatisfação e a revolta" (SD19).

(SD19) O aborto provocado causa, na maioria das vezes, um sentimento de culpa, pela ideia de ter matado uma criança. Além deste sentimento de culpa, com todas as suas perturbadoras conseqüências na pessoa, pode despertar depressão, agressividade contra si mesma e contra o companheiro, no qual se projeta a própria insatisfação e a revolta. ("Aspectos psicológicos do aborto". RH, $\mathrm{N}^{\circ} 790$, mai 1989 , p. 20-1). 
(SD21) E hoje ainda, depois de tudo, quando fala destas coisas, seus olhos verdes se enchem de lágrimas, e ela sente uma angústia, uma tristeza profunda de sentimentos perdidos, que infelizmente, não voltam mais. As coisas que restaram foram dolorosas: vazios, angústias, sentimentos de culpa, a perda do útero e revivências sombrias de momentos estupidamente tristes.

O que acontece é que o aborto provocado, além de trazer conseqüências físicas desastrosas, afeta, e muito a mulher do ponto de vista psicológico, causando grandes danos a nível de sentimentos, percepções, levando a paciente a crises depressivas, de angústia e sentimentos de culpa. ("Aborto, um atentado à vida". FC, N 544, abr 1981, p. 19).

(SD22) Muitas mães contraem sérias infecções ou até perdem a vida com as complicações do aborto. Além disso, será preciso considerar, também, os problemas emotivos e psicológicos relacionados com o aborto provocado. $\mathrm{O}$ choque emocional é muito grande (pelo menos deveria ser) quando o feto abortado já apresenta características visíveis de ser humano como cabeça, olhos, mãos e pés. A reação psicológica da mãe revela uma frustração profunda, pois o aborto praticado a machuca, sem dúvida, de um modo bem visível. E mesmo que ela não veja nada, resta o grave peso de ter rejeitado um filho em gestação (“Aborto: um pecado social”.) FC, $N^{\circ}$ 529, jan 1980, p. 9).

Do julgamento exterior, imputado pelo padre ou pela sociedade, sobressai-se a condenação que se dá na esfera íntima do indivíduo. A dor, a frustração, a tristeza o vazio e o profundo sentimento de culpa evidenciam-se de certa forma como penalidades "suficientes" para as mulheres que praticam o ato. $\mathrm{O}$ discurso da revista, portanto, mostra-se mais propenso a enfatizar as repercussões no âmbito privado do indivíduo do que evidenciar uma punição pública, via "excomunhão automática" (SD129).

Neste contexto, evidencia-se a ação de acolhida por parte da Igreja como mais importante do que a instância de condenação e punição. A superação dos traumas decorrentes do ato do aborto é apresentada como tangível e palpável, podendo ser atingida mediante tratamento psicológico e de uma reaproximação com a religiosidade. O próprio ato de buscar o perdão mostra-se como um passo importante em direção à superação do trauma do aborto.

(SD18) Abortou por achar que não teria outra saída e, por onze anos, um fracasso existencial depois do outro a confirmou na convicção de ser uma rejeitada, indigna de aproximar-se dos sacramentos. A viagem de retorno ou, se preferirem, o início da cura -, coincidiu com o seu encontro com o movimento carismático e com a reconquista da consciência de poder ser perdoada e reacolhida. ("Raquel, não chores mais". $\mathrm{RH}, \mathrm{N}^{\circ}$ 750, out 1985, p. 22).

(SD24) Daí, em geral, a conveniência e quase necessidade de uma terapia ou análise para evitar e superar todos esses conflitos. ("Aspectos psicológicos do aborto". RH, No 790, mai 1989, p.21) 
(SD131) "Na prática - explica Thorn - a mulher que abortou termina por se pôr à margem da vida da Igreja. Sobretudo, não ousa mais dirigir-se aos padres da sua paróquia que a conhecem e dos quais teme, embora erroneamente, o juízo negativo." O "Projeto Raquel" quer ser a resposta a um pedido de ajuda que, embora não seja expresso, nem por isto se apresenta com menores conotações de urgência e angústia.

A sequência seguinte fala sobre um programa católico de auxílio às mulheres que abortaram, promovido pela Igreja norte-americana. O perdão do padre e a terapia psicológica oferecem-se como saída para as sofredoras.

(SD131) Uma propaganda discreta, desenvolvida através das paróquias e dos centros de assistência social, faz conhecer às mulheres com este problema que não só existe a possibilidade de aproximar-se da Igreja, mas que a Igreja está pronta a facilitar a solução. Certa da mais absoluta discrição, a mulher pode dirigir-se aos assistentes sociais que, por sua vez, a encaminharão a padres especialmente preparados para este tipo de reconciliação. Se os seus problemas forem mais sérios, poderá procurar um serviço de counseling, ou seja, de aconselhamento psicológico com pessoal especializado. ("Raquel, não chores mais". RH, $\mathrm{N}^{\circ} 750$, out 1985 , p. 22).

O trecho traz uma interessante articulação entre os valores confessionais e a perspectiva da modernidade, presente na ênfase dada ao "caráter especializado" e extraconfessional do atendimento prestado às mulheres que abortaram. A expressão "mais sérios" delega ao serviço de aconselhamento psicológico uma distinção superior à ação do próprio padre, possibilitando uma leitura que dá a entender ser a psicologia melhor indicada para conferir a solução para os problemas de suas fieis em determinados casos.

\section{CONSIDERAÇÕES}

Um aspecto interessante verificado nesta grande região de sentidos na qual abarcamos a abordagem do aborto em sua dimensão de pecado é que em nenhum momento se remete a um plano ulterior de julgamento, em um nível metafísico. Além daquilo que as revistas efetivamente dizem em seu texto, o "não-dito" aqui nos traz elementos que revelam a forma como as revistas católicas em questão julgam os sujeitos que praticam o ato do aborto.

A cura é descrita como algo tangível e acessível apenas com a ajuda dos padres ou de algum atendimento psicológico e especializado, capazes de propiciar uma "solução" para os casos, mediante o arrependimento e a reconciliação. A questão da "salvação da alma" daquela que "pecou" não aparece como objeto de preocupações diretas, mas sim, a "consciência" atormentada de quem pratica o aborto. Dessa forma, a lógica da culpa e da condenação parece estar sujeita à sentença popularmente descrita como o "aqui se faz, aqui se paga", não 
entrando em jogo uma suposta "condenação para a vida eterna" por consequência da gravidade do "pecado" praticado.

Em relação ao conjunto das designações, numa perspectiva de cotejo entre os domínios discursivos, verifica-se certa uniformidade nos argumentos apresentados por cada um deles. Embora evidenciem diferenças quando aos modos de apresentar a questão, estes não representam aspectos suficientemente relevantes a ponto de exigirem uma abordagem comparativa. No entanto, uma distinção que pode ser salientada é percebida no domínio discursivo Rainha, que denota uma maior presença de relações com a memória interdiscursiva - argumentos bíblicos, relação com memória do holocausto - enquanto Família Cristã privilegia a ênfase ao aborto em sua dimensão social, como um pecado coletivo. Disso poderíamos inferir que o domínio discursivo Rainha operacionaliza de forma mais intensiva os mecanismos de memória enquanto Família Cristã demonstra uma perspectiva mais voltada aos problemas sociais, portanto, maior articulada ao presente histórico daquele momento. Contudo, ambas demonstram postura semelhante ao relativizar a culpabilidade da mulher que aborta, realçando as consequências desse ato como suficientes para puni-las pelo ato que praticaram.

Como evidenciamos no início, o papa Francisco vem demonstrando uma certa virada na orientação de suas explanações em relação aos direitos sexuais e reprodutivos em relação ao seu antecessor, Bento XVI, que frequentemente exprimia declarações condenatórias ao aborto e o casamento homossexual. Mesmo que nossa intenção não tenha sido a de esboçar um estudo comparativo entre os dois momentos históricos, podemos concluir que, o discurso da Igreja Católica, tanto nas vozes expressadas nas revistas como nas declarações recentes do papa, vem tensionando posições contrárias ao aborto sem jamais romper com a formação ideológica da defesa do direito à vida. Neste sentido, o "macroacontecimento aborto" continua a se desenrolar, aglutinando sentidos em torno de sua definição, mas que não deixam de reportar à complexa relação de uma instituição milenar ao contexto da modernidade. 


\section{REFERÊNCIAS}

BENETTI, Marcia. Análise do Discurso em jornalismo: estudo de vozes e sentidos. In.:

BENETTI, Marcia \& LAGO, Cláudia. Metodologia de pesquisa em jornalismo. Petrópolis: Vozes, 2007.

BOURDIEU, Pierre. O poder simbólico. 6 ed. Rio de Janeiro: Bertrand Brasil, 2003.

BRITES, Francine M. "Bento XVI convida à mobilização dos cristãos": discursos católicos em torno do aborto e do direito à vida (1996-2008). Revista Brasileira de História das Religiões. Maringá (PR), V. 3, N. 9, jan. 2011. Disponível em <http://www.dhi.uem.br/gtreligiao/pub.html>. Acesso em 19 jul 2011.

COURTINE, Jean J. Análisis del discurso político (EI discurso comunista dirigido a los cristianos). Tradução de: Analyse du discours politique (le discours communiste adressé aux chrétiens). Langages 62. Juin. 1981. Disponível em:

<http://www.magarinos.com.ar/courtine.htm>. Acesso em 19 jan. 2012.

CUNHA, Anna L. S. da. Pessoa e Direito, Corpo e Ciência: negociando significados e preceitos cosmológicos em torno da legalização do aborto. Dissertação de Mestrado. Brasília: Programa de Pós-Graduação em Antropologia Social, 2007.

DALMOLIN, Aline R. A Rainha de Lauro Trevisan: modernização e religiosidade. Dissertação de Mestrado. São Leopoldo: Programa de Pós-Graduação em Ciências da Comunicação/Unisinos, 2007.

Revista católica: entre o campo Religioso e o Midiático. Anais do XI Congresso de Ciências da Comunicação na Região Sul - Intercom Sul. Novo Hamburgo: Feevale, 2010.

O discurso sobre aborto em revistas católicas brasileiras: Rainha e Família Cristã (1980-1990). Tese de doutorado. São Leopoldo: Programa de Pós-Graduação em Ciências da Comunicação/Unisinos, 2012.

DUARTE, Luiz Fernando D. A vida e as leis (2011). Instituto Ciência Hoje. Disponível em: <cienciahoje.uol.com.br/colunas/sentidos-do-mundo/a-vida-e-as-leis>. Acesso em 21 nov 2011.

FAMíliA CRISTÃ. São Paulo: Paulinas, 1979-1989.

SPADARO, Antonio. Intervista al papa Francesco. La Civiltà Cattolica, Roma, N. 3918, V. 164, 19 set. 2013, pp. 449-477. Disponível em: <

http://www.laciviltacattolica.it/it/quaderni/articolo/3216/scarica-gratuitamente-il-quaderno-n3918-che-contiene-lintervista--a-papa-francesco/>. Acesso em 25 set. 2013.

GRIGOLETTO, Evandra. O discurso de divulgação científica: um espaço intervalar. Tese de doutorado. PPG Letras/UFRGS, 2005. 
INDURSKY, Freda. Da ocupação à invasão: efeitos de sentido no discurso do/sobre MST. In.: INDURSKY, Freda \& FERREIRA, Maria C. Os múltiplos territórios da Análise do Discurso. Porto Alegre: Sagra Luzzatto, 1999, p. 173-186.

LIBARDI DE SOUZA, Estella. Aborto, sexualidade e direitos humanos: o dito nos escritos do judiciário. Anais da VIII Reunión de Antropología del Mercosur (RAM) Diversidad y poder en América Latina. Buenos Aires: UNSAN, 2009. Disponível em 〈http://www.ram2009.unsam.edu.ar/GT/GT\%2019\%20\%E2\%80\%93\%20Perspectivas \%20Antropol\%C3\%B3gicas\%20sobre\%20Sexualidades, \%20Salud\%20y\%20Justicia/GT\%20 19\%20-\%20ponencia(\%20de\%20Souza.pdf>. Acesso em 19 jul 2011.

MAINGUENEAU, Dominique. Novas tendências em Análise do Discurso. 2 ed. Campinas: Editora da Unicamp, 1993.

Análise de textos de comunicação. 5 ed. São Paulo: Cortez, 2008.

MARIANI, Bethânia. O PCB e a imprensa: os comunistas no imaginário dos jornais (1922-1989). Campinas: Ed. Da Unicamp; Rio de Janeiro: Revan, 1998.

MAROCCO, Beatriz. Prostitutas, jogadores, pobres e vagabundos no discurso jornalístico. São Leopoldo: Editora Unisinos, 2004.

MOREY, Miguel. El orden de los acontecimientos: sobre el saber narrativo. Barcelona: Ediciones Península, 1988.

PÊCHEUX, Michel. Semântica e discurso: uma crítica à afirmação do óbvio. 2 ed. Campinas: Unicamp, 1995.

PRADO, Danda. O que é aborto. São Paulo: Brasiliense, 1984 (Coleção Primeiros Passos, N.126).

RAINHA. Porto Alegre: Pallotti, 1979-1989.

SANTA SÉ. Codice di diritto canonico (1983). Disponível em <http://www.vatican.va/archive/ITA0276/_INDEX.HTM>. Acesso em 8 abr. 2010.

TUCHMAN, Gaye. La producción de la noticia. Barcelona: Editorial Gustavo Gili, 1983.

WOITOWICZ, Karina J. A mídia alternativa na defesa dos direitos reprodutivos: discursos sobre o aborto na agenda política feminista. Anais do XXXII Congresso Brasileiro de Ciências da Comunicação. Curtiba: Intercom, 2009. 
Original recebido em: 30/09/2013

Aceito para publicação em: Novembro de 2013

Aline Dalmolin

Bolsista de estágio pós-doutoral CAPES-PNPD no grupo de pesquisa Comunicação, identidades e fronteiras vinculado ao PPG Comunicação da Universidade Federal de Santa Maria. Doutora e mestre em Comunicação pela Universidade do Vale do Rio dos Sinos. Jornalista pela Universidade Federal de Santa Maria. 